Journal of

Education and Practice (JEP)

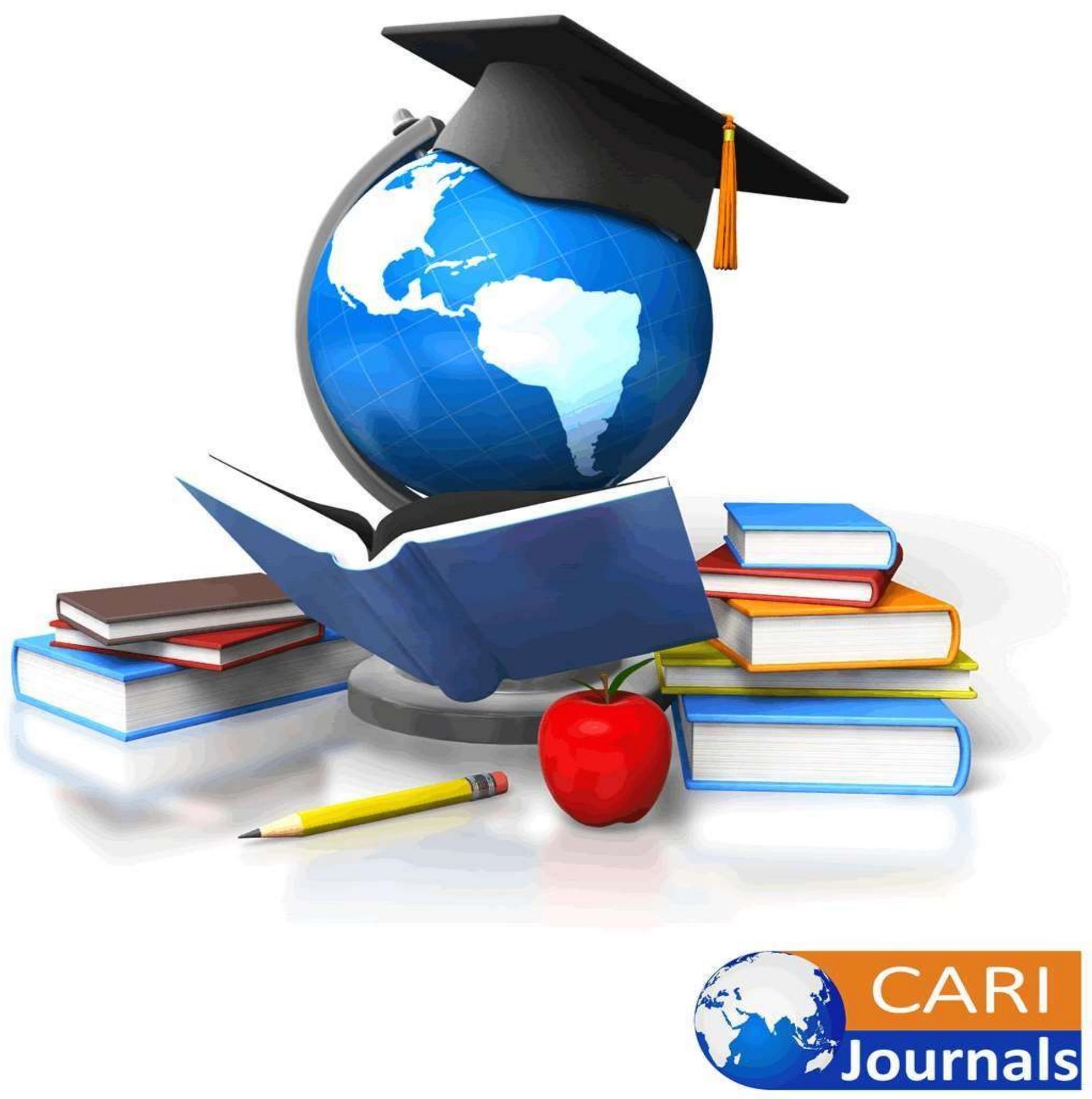




\title{
SYSTEMATIZATION OF RESEARCH INTEGRITY BY REGULATORY BODIES AND UNIVERSITIES IN AFRICA: RESEARCH AND PUBLICATION ETHICS
}

\author{
Lillian Omutoko
}

Corresponding Author's Email: 1illianomutoko@gmail.com

\begin{abstract}
Purpose: Research misconduct is a global ethical concern that imparts negatively on scientific processes and expectations. Other related ethical concerns are academic fraud among researchers in academic institutions. These activities are against the norms of research and academic practice. Some common occurrences in institutions are multiple submission of papers for publication, use of unauthorized assistance or various forms of dishonesty that occur in relation to any academic exercise. Research integrity is a complex multifaceted task that touches on different phases of research. Institutions in Africa barely have policies and structures to uphold research integrity and where they exist, the enforcement mechanisms are not synchronized. Prevention of research misconduct and enforcement of research integrity policies cannot be the responsibility of any single person or institution, it can only be successful if it is a concerted effort. Universities, national bodies and research ethics committees have a major role to play in maintaining research integrity. The purpose of this paper is to explore and develop a systematic approach to enhance research integrity. The paper examines common research integrity issues and proposes pragmatic approaches for preventing research misconduct.

Methodology: The methodology employed was desktop document analysis of related journal articles, guidelines and institutional websites. Case studies of misconduct were reviewed to make sense of types of scientific misconduct that have been recorded in Africa.

Results: Institutions can customize the institutional model according to identified needs and existing structures. The proposed framework would be successful if the efforts are implemented within a multi-thronged approach that includes mentorship and capacity building at all levels for creation of an ethical research culture that enhances credibility of research and builds public trust. Contributions to theory, policy and practice: It is envisaged that the proposed model will improve enforcement of related policies and promote research integrity. A holistic model to streamline prevention of misconduct and nurture a culture of ethical conduct in research is also recommended.
\end{abstract}

Key words: Academic integrity, bioethics, research ethics, research integrity, research misconduct, scientific misconduct

\subsection{Introduction}

Ethical conduct of research fulfils a moral imperative and is a precept for responsible conduct which is variously expressed in various ethical research guidelines (https://wcrif.org/montrealstatement/file;https://www.jsps.go.jp/english/ekousei/data/singap ore statement EN.pdf). Ethical research is credible as it leads to better results and builds the 
trust of participants, communities and the public. Credibility of research depends on upholding the highest ethical standards which inhibit deviations that culminate in transgressions (Shahnazarian, Rose, Hagemann and Aburto, 2017). Research misconduct is a global challenge and the apparent inadequacy of data compounds the problem. It is increasingly becoming difficult to deal with research malpractices because of the undefined process of prevention and difficulties in enforcing sanctions and penalties (Ana, Koehlmoos, Smith \& Yan, 2013). Research misconduct can take place at many points along the research continuum. The Office of Research Integrity in the United States of America (USA) defines research misconduct as fabrication, falsification or plagiarism in proposing, performing, reviewing research or reporting research results (https://ori.hhs.gov/definition-misconduct; Martyn, 2003). Researchers can make honest errors which can be determined through investigation and when confirmed the errors cannot be categorized as research misconduct (Shahnazarian et al, 2017, https://ori.hhs.gov/definitionmisconduct). Investigating and adjudicating research misconduct is challenging because some countries have inadequate policies and structures. When it comes to international collaborative research, there may be conflicting laws, regulations and policies. This may be why the number of papers that are retracted are those that involve authors in partnership involving different countries. (Resnik, Rasmussen, and Kissling, 2015 http://retractiondatabase.org/RetractionSearch.aspx).The casebook by the office of Research Integrity has stories about researchers who have engaged in research misconduct including authorship and publication, collaboration, data acquisition and management, conflict of interest, peer review, mentor and trainee relationships and social responsibility(https://ori.hhs.gov/rcrcasebook-stories-about-researchers-worthdiscussing).

In 2001, the Committee on Publication Ethics reported 51 major cases in Great Britain while the Office of Research Integrity, US inquired into 38 new cases in 1998, 51 in 1999 and 59 in 2000 (Jones, 2002; Martyn, 2003). The Association of British Pharmaceutical Industries identified a significant number of high-profile cases of scientific fraud and the General Medical Council has lots of similar cases (Jones, 2002). In South Africa, there was the Dr. Werner and Bezwoda case in 1990s, data in this study was falsified and fabricated. The Dr. Jon Sudbo study of 2005 which was published in The Lancet and was found to have fabricated data (Moodley, 2017). According to Fang, Steen \& Casadevall (2012) retracted articles were authored in 56 countries comprising Unites States, Germany, Japan and China accounted for 3/4 of retractions. China and India accounted for more cases of plagiarism than USA. In Africa between 2015 and 2019, 32 papers were retracted for reasons ranging from falsification, fabrication, plagiarism, errors in data and data analysis, lack of Institutional Review Board (IRB) approval to limited or no information. While in Kenya, 5 papers involving individual Kenyan researchers and collaborators were retracted for similar reasons (http://retractiondatabase.org/RetractionSearch.aspx). However, except for the cases reported by Retract Watch, there is little evidence of reported cases of research misconduct in low and middle resource countries (Ana, Koehlmoos et al, 2013; Kombe, Anunobi, Tshifungula, Wassenaar, Njadingwe, Mwalukore...Ranaiv, 2014).

Data shows that Argentina and Nigeria lack national and institutional systems while Tunisia has a national system that spells out sanctions but not a system of managing arising cases. (Ana, et al, 2013). A survey that was conducted in Kenya in 2018 revealed that in a population of 100, 52.4\% 
were aware of research misconduct but a majority of the respondents were not cognizant of rules and procedures of dealing with it. Neither were they aware that there are penalties for engaging in the practice. Despite this scenario, over 50\% supported the development of rules and procedures which suggests their recognition of the significance of ethical research. A study on research misconduct reported that most research institutions had experienced between 1-5 cases, with research misconduct being more rampant in academic institutions (Were \& Kamara, 2019).

Notably, the reporting system is extemporized with cases being reported either formally or informally. Some of these cases are dealt with procedurally while others are muted with silence to avoid negative publicity as illustrated by the video on The Lab (https://ori.hhs.gov/TheLab/TheLab.shtml). This emphasizes why records of research misconduct are scanty in Africa. Institutions in Africa have inadequate streamlined procedures for dealing with research misconduct and for quality research to be realized in a trustworthy environment, there is dire need for developing institutionalized administrative structures. Ideally, institutions and mentors need to create a positive research culture that promotes responsible conduct of research. Quite often the demands of academic research environments pressurize students and academic staff to conduct research and publish in an environment that is riddled with time, constraints and deadlines, while scientists are driven by conflicting interests which hampers worthwhile credible and responsible research (Horn, 2013). Many African countries do not seem to have institutional structures except for South Africa which has policies for responsible research misconduct, procedures for investigation and Research Integrity Offices (http://www.researchsupport.uct.ac.za/researchintegrity;http://www.researchsupport.uct.ac. za/officeresearchintegrity;http:/www.sun.ac.za/english/researchinnovation/ResearchDevelopmen t/integrity-ethics). This challenge is mirrored by only a few delegates participating during the 4th World Integrity Conference. The continent was noted to be lagging behind in promoting responsible conduct in research and their perspectives were largely underrepresented. This is why the African Research Integrity Network was established in 2015 to promote research integrity in Africa(http://www.globalhealthethics.org/wpcontent/uploads/2018/08/ARIN-Newsletter1of2018-August.pdf).

\subsection{Methodology}

The methodology that was employed involved desk-top document analysis of journal articles and review of case studies on research misconduct. Google Scholar, PubMed, and JSTOR databases were used to access literature. The authors' experiences as an ethicist have been included to enrich the African scenario.

\subsection{Integrity issues in research}

Research misconduct is an occurrence that continues to be experienced. Historical atrocities in research date as far back as 1932 with the Tuskegee Study of untreated syphilis in Negro males which was an evaluation of the effects of untreated syphilis, the medical experiments that were conducted on human beings by the Nazi physicians in Germany, the experiments were fatal and the Willow brook Hepatitis Study that was conducted at Willow brook State School for mentally 
retarded children (Mellanby, 1947, Brandt, 1978 \& Krugman, 1986). Whistleblowers play a big role in unravelling cases, alarms have often been raised by whistle blowers, for instance, for the Tuskegee Study. In 1965, Dr. Shatz was the first medical professional to object to the study on moral grounds. In 1966 the complaint was ignored and in 1967, Peter Buxtin began an inquiry on morality, however, the panel of physicians did not include African Americans or medical ethicists. Meanwhile Buxtin was still bothered that the objections were not being taken seriously and he contacted the press and in 1972 the results of the assigned reporter were published in July 1972 (Ogungbure, 2011). A case was reported in the press of an Israeli Surgeon who falsely claimed that he and five others had conducted a randomized prospective trial on about 1000 patients between 1992 and 1996 and that he was the sole researcher. It was claimed that it was a prospective study and that informed consent had been obtained whereas it had been conducted retrospectively and consent had not been obtained. The study was presented as an abstract at a conference in Barcelona. This case was investigated by the Public Complaints Officer at the Israeli Ministry of Health (Siegel-Itzkovich, 2007). Other cases of research misconduct have been reported in Nigeria at 91 , with $69 \%$ having been involved in the practice. The study revealed cases of authorship, plagiarism, fabrication and falsification as well as plagiarism at $9 \%$. Falsification of data was attributed to inadequate institutional rules and procedures (Okonta \& Rossouw, 2013).

There is a tendency for researchers in African countries to put emphasis on plagiarism. Fabrication and falsification which are part of the cardinal sins in research seem to be overlooked. Some of the integrity issues that require action are ghost authorship, the order of authorship and intellectual property rights disputes. It is absurd that unreported cases of research misconduct in Africa have often been raised by Research Ethics Committees (RECs) in host institutions collaborating with low resource countries and International journals. At other times whistleblowers have reported cases of concern to RECs which shows the need for streamlining investigation and enforcement procedures. Unfortunately, such cases are not documented.

Authorship issues are an ethical concern that require attention. Cases of flouting publication ethics have been reported in South Africa with a high of 64\% in 2013. This does not mean that other countries in the continent are devoid of the malpractice but rather that authorship problems are yet to be discussed (Ana et al, 2013). Some of the authorship policies in African countries are not engrained in research ethics, for example, the mandatory measure for performance of faculty in Kenya is publications in journals and marks are awarded according to the order of authorship, with the first author getting the most points and the last the least. This scenario creates tension especially where authors are not aware of the reasoning behind authorship and it increases the probability of researchers manipulating situations so that they can be the principal author. This criterion of promotion often culminates in abuse of a system which should essentially promote research integrity. The same system also seems to ignore other parameters of promotion like innovativeness, book and chapter publications, paper presentations in conferences, acquisition of grants, among others. Awarding of weighted points seem to provide a fair playing ground while at the same time it encourages research misconduct. There are also publication issues such as publishing in predatory journals and submission of one paper to different publishers 
https://wcrif.org/montrealstatement/file;https://www.jsps.go.jp/english/ekousei/data/sin gapore statement EN. pdf).

This situation could be the root course of one African University graduating 118 flawed $\mathrm{PhDs}$ and an accumulated 327 over 3 years. Apparently, some academic staff have been reported to have supervised up to 40 postgraduate students and the credibility of some of the students publications were questionable (https://www.nation.co.ke/news/education/CUE-submits-reportJkuats118PhDs/2643604-5197254-11hert2z/index.html). This case was brought afore by whistleblowers through social and print media which raises the need for a policy on safeguarding those who report alleged cases of misconduct. Some scholars and research regulators argue that countries should graduate high numbers of PhDs to leverage research and innovation. While this may be true, it should not be at the expense of sound research (Bwisa, 2019). Responsible authorship is a virtue that needs to be invested in so that every author who participates gets due credibility for their contribution based on the significance of their input. The issues that usually arise in authorship include the order of authorship and ghost authorship also referred to as gift authorship. To avoid authorship wrangles, research teams can have a memorandum of understanding before engagement based on the significance of their contribution so that complaints do not arise later and each author would then get a genuine share of recognition. The challenge that is often faced by researchers is that there is no clear criteria for authorship and this is why disagreements are common. There are virtually no guidelines and cases of authors gifting their friends or people who have not participated in the process are included as authors in publications, these are the authors who are labelled as guest or ghost authors.

\subsection{Efforts to Promote Research Integrity in Research Institutions}

A frequent question that arises in various forums on the regulation of research and protection of human participants is whether institutions have the capability to handle research misconduct. Universities are viewed as a good platform for sensitization and promoting research integrity. Research integrity is a positive initiative that aims at counteracting research misconduct it touches upon the entire research process through to publication. Minimal efforts have been made in developing countries to counter research misconduct which points to the need for institutionalization of research integrity and development of policies. In some institutions especially higher education institutions research offices have been established at high management levels including Directorates of Research, however, there are no specific research integrity offices which means that there are no systems and procedures for handling cases (Were \& Kamaara 2019, www.uonbi.ac.ke).

Some universities have procured anti-plagiarism soft wares and require that all scholarly research work have to be submitted with anti-plagiarism reports at the ethics approval level, proposal and final defense. This helps in handling one aspect of research misconduct, however, the challenge here is that the anti-plagiarism test is often not centrally managed which provides ground for abuse such as manipulation of the report and bribery in the offices that assist researchers to run the test. On the same note other forms of research misconduct seem to have been ignored. The Research Integrity Project that was conducted in Kenya between 2018 and 2019 suggested implementation 
of an institutional framework for management of research misconduct which would be steered by established Research Integrity Offices who would be responsible for inquiry, investigation and adjudication of alleged misconduct. The process would also include safeguards for informants and enforcement of sanctions and penalties. This reiterates the need for development of policies, guidelines and increase of institutional capacity in all research institutions (Committee on Responsible Science, 2017, Were and Kamaara, 2019). The resultant structure would then enforce sanctions and penalties in line with the developed institutional research misconduct policy.

\subsection{Publication Ethics for prevention of authorship and credit disputes}

Global efforts have been made to come up with strategies to prevent authorship and credit disputes. Retraction is a prime indicator of misconduct, it helps in curtailing unethical conduct among researchers, nonetheless, most developing countries are yet to introduce systematic processes. Articles are retracted when findings are no longer considered trustworthy due to scientific misconduct or when previously published work has been plagiarized or there has been violation of ethical principles. The frequency of retraction can be measured using 'the retraction index' and the test has previously shown that the frequency of retraction among journals shows a strong correlation with the journal factor, this notwithstanding most scientific journals lack a retraction policy (Fang \& Casadevall, 2011).

PubMed evidences more than 25 million articles related to biomedical research since the 1940s. In 2012, there were 2,047 retracted articles, with the earliest retracted article in 1973 and 1977. To deter misconduct, retraction announcements are usually made in scientific journals and journal websites. Nevertheless, because of inadequate systems and lack of retraction policies it is not clear what happens to reported cases (Fang et al, 2012). The committee on Publication Ethics Guidelines (COPE) has guidelines for Retraction of Articles. The guidelines guide on what journal editors need to do when considering retracting a publication, that is, issuing an expression of concern and issuing a correction of concern; what publication should be retracted, the form the retraction should take and who should issue a notice of retraction (COPE, 2009). Publishers ought to use these guidelines and better still develop their own. The International Committee of Medical Journal Editors (ICMJE) gives recommendations for reviewing best practice and ethical standards in the conduct and reporting of research, to help authors and editors and others involved in peer review and publication of scholarly work in medical journals (ICMJE, 2018). The Singapore Statement on Research integrity has proved to be very useful in explicating principles of research which provide a basis for developing guidelines on research integrity and capacity development (https://www.jsps.go.jp/english/e-kousei/data/singapore statement EN.pdf).

Due to the special challenges faced in international collaborations, The Montreal Statement on Research Integrity in Cross-Boundary Research Collaborations explains the responsibilities of researchers so that they can address differences emanating from the collaborations and issues related to integrity arising from cross-border research collaborations (3rd World Conference on Research Integrity, 2013). Publishers also have a significant role to play by taking sanctions such as article correction, withdrawal and removal. Upon identification and investigation of flaws, journal editors will publish and disseminate the corrective notice, publish a notice, corrigendum or 
erratum. The editors will make a formal retraction for most matters including publication of a corrective notice with a direct link to the original article and formal removal. Although formal removal is in very rare cases because of the importance of maintaining the scientific record. Editors also publish an editorial discussing the matter or decision by the editorial board on future submissions by the author or author group. Additionally, credible journals check plagiarism and debar guilty authors from publishing for a certain period though this is rare. The notion of banning authors is against publication tradition because the editorial process is meant to encourage authors and it is expected that after giving an author or authors several chances, they will learn proper publication rules (AtlantisPress,https://www.atlantis-press.com/policies/articleretraction-andwithdrawal,Elsevier,https://www.elsevier.com/editors/perk/questions-andanswers) . From the aforementioned, it is evident that development of a holistic model will help in prevention of misconduct and nurture a culture of ethical conduct in research.

The efforts to promote research integrity are however dismal in Africa and amidst the efforts there are still numerous shortcomings in resolving research misconduct in that there are no direct punitive measures in place which has culminated in those who get offended in the process of research to resort to seeking legal redress which is not quite a solution because the process is often costly, delayed and cumbersome. Cases that are reported and handled in court have not quite helped in solving the problem rather they have been viewed as drawing undesired negative attention to concerned institutions.

\subsection{Policy Development and Regulation of Research}

Regulation of research especially research involving human participants is increasingly becoming a worldwide concern. Several countries have failed to establish a comprehensive response to research misconduct that incorporates prevention, investigation, punishment and correction. The United States, Scandinavian countries and Germany have formal programs; however, the United Kingdom has failed to respond appropriately (Tavare, 2011; Godlee, 2012). In the US, The Office for Human Research Protections (OHRP) and the Office of Research Integrity have systems that influence research management, these efforts are augmented by national research regulatory bodies. Nonetheless, the role of the latter in promoting research integrity is not quite concrete and requires streamlining (Horn, 2013). Most African Countries have RECs to uphold compliance to research ethical guidelines and uphold responsible conduct of research although some of the RECs still require capacity building to increase their competence. Notably, Africa needs policies and governance systems to promote responsible conduct of research (Kombe et al, 2014).

Africa can benefit from international models for responding to misconduct. The Council of Science Editors have made recommendations for identification of misconduct and guidelines for action, while the World Association of Medical Editors makes suggestions on responding to misconduct allegations. The Singapore Statement presents principles and professional responsibilities and the Montreal Statement presents collaborative responsibilities, relationships, managing collaborations and responsibilities for outcomes of research (https://wcrif.org/montrealstatement/file; https://www.jsps.go.jp/english/ekousei/data/singapore statement EN.pdf; Wiley,2014). 
It is advisable to develop homegrown institutional strategies for promoting responsible research. This can include a holistic approach that entails compliance to ethical research guidelines, regulatory rules and regulations as stipulated by research regulatory bodies, training, mentorship, development of institutional policies and strategies that enhance responsible conduct of research (Horn, 2013; Kombe, et al, 2014). For researchers to uphold research integrity, they must keep abreast with the international, national and institutional codes of ethics. Whereas these may be available, the challenge is institutions may not have relevant codes or where they are available, researchers may not be aware. This requires that these codes are posted in institutional websites and university management spearhead sensitization to promote research integrity. On the same note research regulatory bodies and RECs ought to augment institutional efforts (Horn, 2013). South Africa has put in effort by developing capacity on protection of human research participants and promotion of research integrity. They have guidelines for good clinical practice, principles, structures and processes for ethical health research (Department of Health, 2004; 2006). The National Health Act No.61 of 2003 provides regulations relating to storage and use of biological samples, establishment of research committees, identification of health research priorities and research on human experimentation with subjects (Government Gazette, 2004).

For international collaborative research to be beneficial, it must be reliable and trustworthy, therefore the need for promotion of research integrity. Horn (2016) proposes the establishment of research integrity offices in Africa. In United Kingdom, the UK panel of Research Integrity in Health and Biomedical Sciences established a helpline in Edinburg to offer guidance to whistleblowers who may have uncovered cases of misconduct in medical research, it offers expert advice to universities to help them respond to allegations of research misconduct because of consequences of research misconduct on humans and financial implications. The helpline is meant to introduce transparency in dealing with research misconduct, this is one of the possible ways of helping to promote research and academic integrity (Siegel-Itzkovich, 2007). To build on this, all key players in research need to be involved in development of research policies and regulation of research. These players would include National Research Regulatory bodies, National Bioethics Committees (NBC), Higher Education Institutions (HEIs) and Research Management \& Development offices and Ministry of Education or the equivalent of Ministry of Education. These institutions would be responsible for development of legal procedures and laws on which the other institutions can anchor respective policies and codes. This is in concurrence with Okonta \& Rossouw, (2013) who argues that enforcement of research integrity policies would be more viable at national and institutional level. These stakeholders need to build synergy because their concerted efforts would contribute greatly in synchronizing and coordinating efforts to realize research integrity. Figure 1 is a model showing how research integrity can be dealt with at the national level, with the Ministry of Education and National Research Regulatory bodies playing the overarching role. Stakeholders need to work together for promotion of responsible conduct of research. 


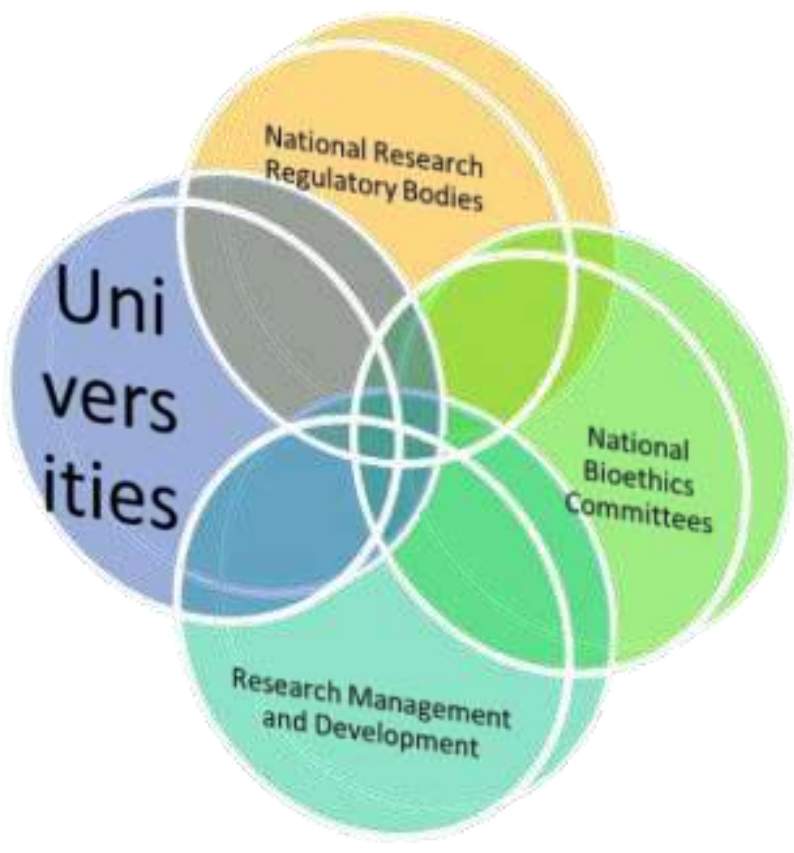

\section{Fig 1: Model for Policy Development and Regulation of Research}

For actualization, the efforts by government bodies would have to be cascaded to institutions who will then develop frameworks and guidelines to guide research integrity, regulate research and advise management on research related issues. Bearing in mind the intricacies of research integrity the institutions can guide legislative interventions and development of policies for preventing research misconduct. They can also spearhead benchmarking in countries that have developed structures for handling research misconduct (Kombe et al, 2014; Akan et al 2013). Figure 2 is a model for institutional management of research misconduct. Ministry of Education and the National Research Regulatory body would be at the apex to play an oversight role. Research Ethics Committees (RECs) have a stake in enhancing responsible conduct in research. They are mandated to review and approve research with the underlying principle being protection of research participants, it is also their responsibility to ensure that research that is conducted is credible and that the highest ethical standards are upheld. Since RECs are independent, they are tasked with the responsibility of protecting the rights and welfare of research participants, they also play a major role in the pursuit of research integrity by assessing related ethical issues like research misconduct and plagiarism (Grady, 2015; UNESCO, 2005). Institutions can be relied on to develop a normative framework for promoting research integrity through development and enforcement of policies and guidelines. In practice, RECs are hosted by research institutions and universities. The hosting institutions should then establish research integrity offices, intellectual property rights and grant management offices to deal with misconduct and other related concerns. 


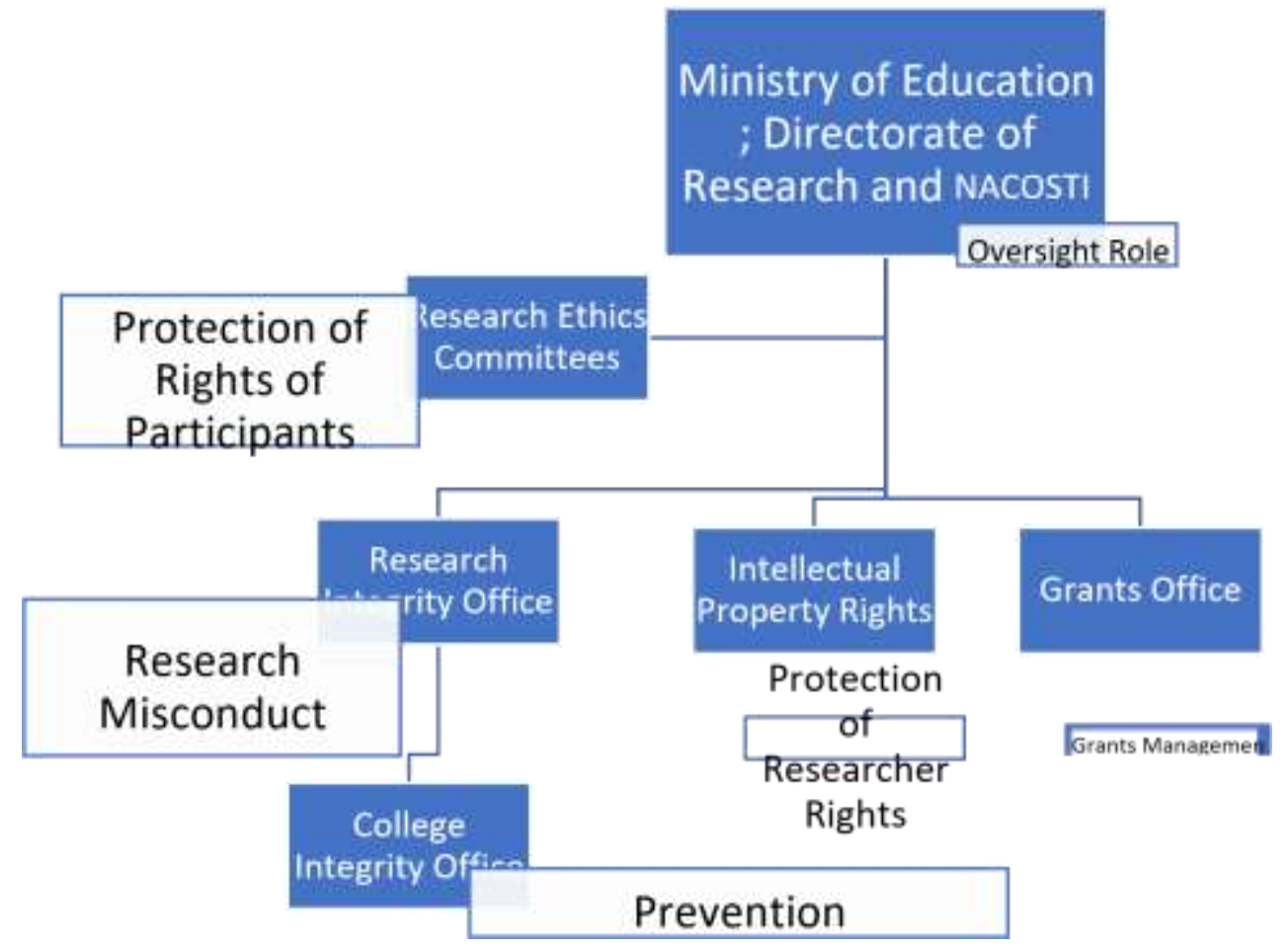

Fig 2: Institutional Management Model 7.0 CONCLUSION AND RECOMMENDATION

These models are informative and advisory in nature and can be viewed as a guide for developing the much needed structures at the national and institutional levels for promotion of research integrity in Africa because of increased research and international collaborations involving low and high resourced countries. Institutions can customize the institutional model according to specific need and existing structures. The proposed framework would be successful if the efforts are implemented within a multi-thronged approach that includes mentorship and capacity building at all levels for creation of an ethical research culture that enhances credibility of research and builds public trust.

\section{References}

Africa Research Integrity Network (2018). Working Together Towards Promoting Research Integrity in Africa. http://www.globalhealthethics.org/wpcontent/uploads/2018/08/ARINNewsletter-1-of-2018-August.pdf

Bierer, B.E. (2010). Case Studies: Authorship Questions. https://www.brighamandwomens.org. Accessed 4th August 2017

Brandt, Allan M. 1978. "Racism and research: The case of the Tuskegee Syphilis study." The Hastings Center Report 8(6): 21-29. https://www.jstor.org/stable/3561468. Retrieved on 23rd September 2019 at 5.24 
(Bwisa, H. 2019). JKUAT should produce more than $118 \mathrm{PhD}$ graduates at any given one given graduation http://profbwisa.mukmik.co.ke/index.php/2019/07/14/jkuat-should-producemorethan118-phd-graduates-at-any-one-given-graduation/

Committee on Publication Ethics (COPE). (2009). Retraction Guidelines. www.publicationethics.org.https://publicationethics.org/files/retraction\%20guidelines_0.pdf.

Committee on Responsible Science (2017). Fostering Integrity in Research. National Academic Press. https: //www.ncbi.nlm.nih.gov/books/NBK475953/pdf/Bookshelf_NBK475953.pdf. Retrived on 25th September 2019 at 5.36

Commission of University Education (2014). Harmonized Criteria and Guidelines for Appointment and Promotion of Academic Staff in Universities in Kenya http://www.cue.or.ke/images/news/appointment_promotion_criteria_universities_2014.pdf

CUE submits report on JKUAT's 118 PhDs to Education Ministry. https://www.nation.co.ke/news/education/CUE-submits-report-Jkuat-s-118PhDs/2643604519725411hert2z/index.html

Department of Health. Republic of South Africa (2006) (Ed).Guidelines for Good Practice in the Conduct of Clinical Trials with Human Participants in South Africa.

Department of Health. Republic of South Africa (2004). Ethics in Health Research: Principles, Structures and Processes.

Fang, F.C., Steen, R.G. \& Casadevall, A. (2012). Misconduct accounts for the majority of retracted scientific publications. Proceedings of the National Academy of Sciences of the United States of America (PNAS). 109(42) 17028-17033 https://www.pnas.org/content/109/42/17028.https://doi.org/10.1073/pnas.1212247109

Fang, F.C \& Casadevall, A. (2011). Retracted Science and the Retraction Index. American Society for Microbiology. 79(10) pp. 3855-3859. DOI: 10.1128/IAI.05661-11. https://iai.asm.org/content/79/10/3855.short

Government Gazette No.26595 (2004).National Health Act No.61, 2003

Grady, C. (2015). Institutional Review Boards. Purposes and Challenges. Chest 148(5).1148-1155. https://www.ncbi.nlm.nih.gov/pmc/articles/PMC4631034/. doi:10.1378/chest.15-0706

Krugman, S. (1986). The Willowbrook Hepatitis Studies Revisited: Ethical Aspects. Reviews of 
Infectious Diseases. Vol.8 (1) pp.157-162. https:/www.gvsu.edu/cms4/asset/F51281F000AFE25A5BF632E8D4A243C7/willowbrook_hepatitis_studies.pdf. Retrieved on 23rd September 2019 at 5.09

Horn, L. (2016). Promoting Responsible Research Conduct: A South African Perspective. Journal of Academic Ethics. Vol. 15(1) pp. 59-72. Retrieved from https://link.springer.com/article/10.1007/s10805-016-9272-8

Horn, L. (2013). Promoting responsible research conduct in a developing world academic context. South African Journal of Bioethics and Law. Vol.6 (1) pp. 21-24. Retrieved from https://www.ajol.info/index.php/sajbl/article/view/90037/79494

International Committee of Medical Journal Editors (ICMJE) (2018). Recommendations for the Conduct, Reporting, Editing, and Publication of Scholarly Work in Medical Journals.

http://www.icmje.org/icmje-recommendations.pdf. www.icmje.org

Jones, R. (2002). Research Misconduct .Family Practice. Vol.19 (2). Oxford University Press. Great Britain. https://watermark.silverchair.com/190123.pdf

Keymanthri, M. (2017). Medical ethics, law and human rights. A South African perspective. Van Schaik. South Africa.

Kombe, F. Anunobi, E.T., Shifungula, N.P., Wassenaar, D., Njadingwe, D., Mwalukore, S.,Chinyama,J., Randrianasolo,B., Akinde,P., Dlamini, S.,Ramiandrusoa,F.N. \& Ranaivo (2014). Promoting Research Integrity in Africa: An African Voice of Concern on Research Misconduct and the Way forward. Developing World Bioethics 14(3) pp.158-166. doi: 101111/dewb.12024

Martyn, C. (2003). Fabrication, falsification and plagiarism. An International Journal of Medicine, Vol. 96(4) pp. 243-244.https://www.ncbi.nlm.nih.gov/pmc/articles/PMC2052883/0026.pdf

Mellanby, K. (1947). Medical Experiments on Human Beings in Concentration Camps in Nazi Germany. British Medical Journal pp.148-150.

https://www.ncbi.nlm.gov/pmc/articles/PMC2005883/pdf/brmedj037-0026.pdf. Retrieved on 23rd September 2019 at 18.06

Montreal Statement on Research Integrity in Cross-Boundary Research Collaborations. https://wcrif.org/montreal-statement/file. Retrieved on $23^{\text {rd }}$ April 2019 at 19.53

Stellenbosch University. Policy for Responsible Research Conduct at Stellenbosch University.https://www.sun.ac.za/english/policy/Documents/Research\%20Ethics\%20Policy.pdf. Retrieved on 1th September, 2019 at 18.45 
Stellenbosch University. Research Integrity and Ethics. http://www.sun.ac.za/english/researchinnovation/Research-Development/integrity-ethics

Ogungbure, A.A. (2011). The Tuskegee Syphyllis Study: Some Ethical Reflections. Thought and Practice: A Journal of the Philosophical Association of Kenya (PAK). New Series, Vol. 3(2).pp7592. https://www.ajol.info/index.php/tp/article/download/74876/654/65

Office of Research Integrity. https://ori.hhs.gov/definition-misconduct

Office of Research Integrity. Avoiding Research Misconduct. https://ori.hhs.gov/the-lab

Okonta, P. \& Rossouw, T. (2013). Prevalence of Scientific Misconduct among a Group of Researchers in Nigeria. Developing world bioethics. 13(3):149-57 https://onlinelibrary.wiley.com/doi/abs/10.1111/j.1471-8847.2012.00339.x:

https://doi.org/10.1111/j.1471-8847.2012.00339.x

Organization for Economic Co-operation and Development Global Science Forum (2017). Best Practices for Ensuring Scientific Integrity and Preventing Misconduct. http://www.oecd.org

Resnik, D. B., Rasmussen, L.M. and Kissling, G.E. (2015). An International Study of Research Misconduct Policies. Accountability in Research Policies and Quality Assurance.22 (5):249-66. DOI:10.1080/08989621.2014.958218.https://www.researchgate.net/publication/275666303_An International_Study_of_Research_Misconduct_Policies

Siegler-Itzkovich, J. (2007).Israeli Surgeons Put Their Names on Study They Had Not Done. BMJ: British Medical Journal. Vol. 334(7602) p.1023. Retrieved from https://www.jstor.org/stable/20507168?readnow=1\&refreqid=excelsior\%3A0095118f5ed728398 8c2da861403c31d\&seq=1\#page_scan_tab_contents

Shahnazarian, D., Rose, S.L.,Hagemann, J. and Aburto, M.(2017). Avoiding Being Penalized: Research Misconduct. University of Southern California. https://oprs.usc.edu/files/2017/05/Whatis-Research-Misconduct-4.5.13.pdf

UNESCO (2005). Establishing Bioethics Committees. UNESCO. France. Retrieved from https://unesdoc.unesco.org/ark:/48223/pf0000139309

University of Cape Town. Office of Research Integrity. Retrieved from: http://www.researchsupport.uct.ac.za/office-research-integrity. Retrieved on 16th September 2019 at 17.25

University of Cape Town. Research Integrity. Retrieved from: http://www.researchsupport.uct.ac.za/researchintegrity. Retrieved on 16th September, 2019 at 
17.00

Were, E. and Kamaara, E. (2019).Research Misconduct:- a problem in Kenya as well.https://irec.or.ke/wp-content/uploads/2019/03/Research-Misconduct-a-problem-inKenyaaswell-E-WERE-KAMAARA.pdf. Retrieved on 25th September 201

Wiley (2014). Best Practice Guidelines on Publication Ethics. (Ed).John Wiley \& Sons Ltd. https://authorservices.wiley.com/asset/Ethics_Guidelines_7.06.17.pdf

World Conference on Research Integrity (2013). Montreal Statement on Research Integrity in Cross-Boundary Research Collaborations. https://wcrif.org/montreal-statement/file

World Conference on Research Integrity (2010). Singapore statement on research integrity. https://www.jsps.go.jp/english/e-kousei/data/singapore_statement_EN.pdf 